\title{
Towards modelling flood protection investment as a coupled human and natural system
}

\author{
P. E. O'Connell and G. O'Donnell \\ Water Resource Systems Research Laboratory, School of Civil Engineering and Geosciences, \\ Newcastle University, Newcastle upon Tyne, UK
}

Correspondence to: P. E. O'Connell (enda.oconnell@ ncl.ac.uk)

Received: 3 June 2013 - Published in Hydrol. Earth Syst. Sci. Discuss.: 27 June 2013

Revised: 9 November 2013 - Accepted: 17 November 2013 - Published: 14 January 2014

\begin{abstract}
Due to a number of recent high-profile flood events and the apparent threat from global warming, governments and their agencies are under pressure to make proactive investments to protect people living in floodplains. However, adopting a proactive approach as a universal strategy is not affordable. It has been argued that delaying expensive and essentially irreversible capital decisions could be a prudent strategy in situations with high future uncertainty. This paper firstly uses Monte Carlo simulation to explore the performance of proactive and reactive investment strategies using a rational cost-benefit approach in a natural system with varying levels of persistence/interannual variability in annual maximum floods. It is found that, as persistence increases, there is a change in investment strategy optimality from proactive to reactive. This could have implications for investment strategies under the increasingly variable climate that is expected with global warming.

As part of the emerging holistic approaches to flood risk management, there is increasing emphasis on stakeholder participation in determining where and when flood protection investments are made, and so flood risk management is becoming more people-centred. As a consequence, multiple actors are involved in the decision-making process, and the social sciences are assuming an increasingly important role in flood risk management. There is a need for modelling approaches which can couple the natural and human system elements. It is proposed that coupled human and natural system (CHANS) modelling could play an important role in understanding the motivations, actions and influence of citizens and institutions and how these impact on the effective delivery of flood protection investment. A framework
\end{abstract}

for using agent-based modelling of human activities leading to flood investments is outlined, and some of the challenges associated with implementation are discussed.

\section{Introduction}

Due to the perceived threat from climate change, prediction under changing climatic and hydrological conditions has become a dominant theme of hydrological research. Much of this research has been climate-model-centric, in which general circulation model/regional climate model (GCM/RCM) climate projections have been used to drive hydrological system models to provide predictions of impacts that should inform adaptation decision-making. However, adaptation fundamentally involves how humans may respond to increasing flood and drought hazards by changing their strategies, activities and behaviours, which are coupled in complex ways to the natural systems within which they live and work. Humans are major agents of change in hydrological systems, and representing human activities and behaviours in coupled human and natural hydrological system models is needed to gain insight into the complex interactions that take place, and to inform adaptation decision-making.

Due to the apparent threat from global warming, governments and their agencies are under pressure to make proactive investments to protect people living in floodplains from the perceived increasing flood hazard. However, adopting this as a universal strategy everywhere is not affordable, particularly in times of economic stringency, and also since widespread solid evidence of increasing flood hazard 
induced by global warming has yet to emerge (IPCC, 2012). Matalas (1997) has suggested that, in a water resources context, the strategy of "wait and see" - i.e. delaying the making of important, expensive and essentially irreversible capital investments - could serve water managers well in coping with the uncertainties regarding climate change. Investment in flood protection infrastructure has frequently been reactive. During "flood-poor" periods when no major floods occur, encroachment on floodplains and the value of assets grow, while levels of flood protection investment decline; conversely, during "flood-rich" periods when major floods occur, leading to major damage and possibly loss of life, there is public outrage and investment grows, i.e. is reactive. The process that determines when and where investments take place increasingly involves interactions between a range of stakeholders, from those making government policy to individual floodplain dwellers. There is increasing evidence, particularly in the wake of major floods, that pressures can be exerted by stakeholder groups that have been affected, or might be affected in the future, by flooding, resulting in investments which are driven by such pressures and not by the traditional "rational" norms of cost-benefit analysis or utility theory.

The hydrological research literature on flooding has historically been dominated by the engineering hydrology approaches that underpin the design of flood protection works. As the impacts of floods on society have grown, the narrow flood protection approach has evolved into broader flood risk management (FRM) approaches that consider the economic, social and environmental dimensions of sustainability, and a portfolio of both structural and non-structural measures for addressing flood risk. The non-structural measures typically focus on the need for more structured approaches to land use management/development in floodplain areas, better institutional functioning, better flood warning and emergency service operation, and the development of flood resilience (McEwen and Jones, 2012; McEwen et al., 2012a). The social science literature on the complex socio-economic dimensions of flooding has therefore grown, and encompasses institutional analysis, the social impacts of flooding and how to address them, the evolution of flood protection investment policies, and reactive institutional responses to major flood events. While there is evidence of increasing engagement between engineers and social scientists in developing interdisciplinary approaches to flood risk management, it is still the case that there is something of a "paradigm lock" between the quantitative modelling approaches of flood hydrology and the more qualitative approaches that characterise the social sciences. Sivapalan et al. (2012) have proposed developing the new paradigm of socio-hydrology as a means of incorporating the social dimension into hydrological research. As a contribution to socio-hydrology, Di Baldassarre et al. (2013b) have recently proposed a conceptual framework to describe the interactions and feedback mechanisms between hydrological and social processes in settled floodplains.

In dealing with the problem of how to model adaptation investment strategies, there is the key issue of how to represent the possible ways in which human activities at various levels, ranging from policy-making/decision-making on investments to the tactics of individual floodplain dwellers in seeking to gain better protection, might be modelled. Agentbased modelling $(\mathrm{ABM})$ offers interesting possibilities in this regard, and these are explored in this paper.

The overall aim of this paper is to explore how a coupled human and natural system (CHANS) modelling approach to determining flood investment strategies might be formulated and developed. Two specific aspects are investigated:

1. The performance of proactive and reactive investment strategies is explored, in terms and costs and economic damage over a design life, using rational cost-benefit analysis in the first instance, and a Monte Carlo approach to modelling floods with high levels of persistence/interannual variability in the natural system, to mimic flood-rich and flood-poor periods

2. The way in which multiple stakeholders interact to influence/determine flood investment decisions is reviewed, and we explore how the human system component of a CHANS modelling approach to flood protection investment might be represented. In particular, we focus on how agent-based modelling might be used to represent the various stakeholders that are involved in, or influence, flood protection investment, and the interactions that take place between them, in determining when and where in a region flood investments take place.

\section{Institutional responses to changing flood risk}

The inexorable rise in flood damage across Europe and beyond (Munich Re, 2008; Barredo, 2009) that has resulted from a series of major floods (e.g. the Oder, 1997; the Yangtze, 1998; the Elbe, 2002; the Rhone, 2003; the Danube, 2006; central Europe, June 2013; and in the UK, 2000, 2007 and 2009) has led to major policy reviews by many countries on how to deal with increasing flood risk. This is attributable both to the growth in vulnerability of people and their property, priority and economic activities in floodplains, and to the possible increase in flood hazard from global warming. This reappraisal has also been driven by the EU Floods Directive (Directive 2007/60/EC), which requires that flood risk management plans must be prepared and published by member states, and that stakeholder engagement should be an integral part of this process. The need for those stakeholders affected by, or at risk from, floods to be involved has also been driven by public outrage following major floods; stakeholders have attitudes and aspirations, and voices that need 
to be heard when decisions are being taken by the responsible agencies that affect them. The media also play a role in post-flood inquests, and ramp up the pressure on politicians and government agencies for changes in policy, increased investment in flood protection, and implementation action. It is frequently the case that policy changes are crisis-driven, and that catalytic change results only as a consequence of major flood crises (Penning-Rowsell et al., 2006).

Following a series of damaging floods in the UK in the 1990s and the year 2000, the government recognised that the traditional approach of providing protection to all those at risk was not economically viable. The UK Office of Science and Technology (OST) Future Flooding project (Evans et al., 2004a, b) developed the thinking for a new, more holistic approach to managing flood risk, which has now been taken on board in formulating the new government strategy for managing flood and coastal erosion risk in England - "Making Space for Water (MSW)" (Defra, 2004). This holistic MSW approach is risk-driven and requires that adaptability to climate change becomes an integral part of all flood and coastal erosion management decisions. A whole catchment and whole shoreline approach is being adopted that is consistent with, and contributes to, the implementation of the EU Water Framework Directive. The MSW strategy requires the consideration of a broad portfolio of response options for managing risks including changes to land use planning in flood-prone areas, urban drainage management, rural land management and coastal management as part of the integrated holistic approach. Similar responses to managing future flood risk are being taken in other European countries, including "Room for the River" in the Netherlands (Wiering and Driessen, 2001) and "Room for Rivers" in Germany (Krieger, 2012). There is to be more emphasis on warning, adaptation, and emergency planning. Stakeholders are to be engaged at all levels of risk management, with the aim of achieving a better balance between the three pillars of sustainable development (economic, social and environmental) in all risk management activities (Defra, 2005). The requirement for stakeholder participation is steered also by the EU Water Framework Directive's and the EU Floods Directive's requirements to involve participatory methods in water/flood risk management planning. One consequence of this is an increasing focus on how key elements of flood risk management planning can be implemented at community level, where the impacts of flooding have occurred, or might occur, in the future.

The increasing involvement of local communities in flood risk management has implications for how investments in flood protection infrastructure are being made, and will be made in the future. Decision-making processes relating to investments are becoming increasingly participatory and require "transparent targets" (Johnson and Priest, 2008); i.e. there is a shift from a top-down state-centred approach towards one in which other organisations, agencies, local pressure groups and individuals are playing an increasing role. The traditional top-down models for investment in flood protection infrastructure have either been standardbased (e.g. the $100 \mathrm{yr}$ flood), or evaluated using a costbenefit approach, with at-risk sites prioritised on the basis of a benefit/cost (B/C) ratio, for example. At a time when the economies of many countries are struggling, state allocations of funds for investment in all sectors, including flood risk management, are under threat or are being reduced, and so the competition for scarce funds is increasing. While the traditional B / C approach still has a dominant role in determining which sites are prioritised for investment in the UK, there is evidence of new funding models emerging in which state level funds are augmented by local government agency funds to enable some sites to move up the priority queue and gain state funding that would otherwise not be gained based on a B / C criterion. Political pressures at local level play a role in this. This co-funding model will inevitably create winners and losers, and raise questions about equity and fairness in investment allocation. On the other hand, it marks a shift in responsibility for flood risk management downwards and outwards that means that those affected by flooding have an increasing role to play in flood risk management, and presages increasing cooperation between the state, operating agencies and public bodies and citizens, which is highly desirable.

One area of flood risk management in which local communities have a key role to play is in building flood resilience. While it is well recognised that technical developments in flood science provide essential underpinning to improved flood risk management, a key question for UK resilience planning is how different and wider flood knowledge bases can be built into the policy process and sustainability governance at the local, lay, level (McEwen and Jones, 2010). To develop flood knowledge beyond the "strategic/managerial/expert" levels requires different conceptual frameworks, knowledge and skills which operate at the community, family and individual levels. McEwen and Jones (2012) discuss the role of local/lay flood knowledge in building community resilience post the 2007 floods in Gloucestershire, UK, which caused economic damage valued at more than GBP 3 billion. They reflect on how flood knowledge can be captured, used and harnessed in flood resilience planning, and on the role of local knowledge and "sustainable flood memory" in developing community flood resilience. They conclude that the 2007 UK flood experience is generating new understandings of the value of local knowledge, and how this knowledge might be successfully used in flood risk management practice. Further, McEwen et al. (2012b) advocate the concept of sustainable flood memory for effective flood risk management. Sustainable flood memory is conceived as community-focused, archival, integrating individual/personal and collective/community experiences, and involving inter- and intra-generational communication and strategies for incorporating it into flood risk management (McEwen et al., 2012b). This is clearly 
necessary when there are "flood-rich" and "flood-poor" periods to avoid vulnerability growing in the latter periods.

\section{Coupled human and natural systems}

An increasing focus on coupled human and natural systems (CHANS) and how to model them has developed primarily within the literature on ecological systems and their sustainability. A review of this extensive literature is beyond the scope of this paper; selected papers are referenced here to provide an indication of how this interdisciplinary field is developing, particularly the characterisation/modelling of the human system, and the coupling/integration of the natural and human systems.

Liu et al. (2007b) provide a well-structured, informative overview of CHANS research. Firstly, CHANS research focuses on the patterns and processes that link human and natural systems. Second, CHANS research emphasises reciprocal interactions and feedbacks - both the effects of humans on the environment and the effects of the environment on humans, climate change being the paramount example of this. Third, understanding within-scale and crossscale interactions between human and natural components is viewed as a major challenge for the science of CHANS. Liu et al. (2007b) synthesise major characteristics of complex organisational couplings (among organisational levels), spatial couplings (across space), and temporal couplings (over time) of CHANS, and discuss their implications for sustainable environmental/natural resource management and governance. Liu et al. (2007a) review complex patterns and processes in CHANS which are not evident when studied by social or natural scientists separately. A synthesis of six case studies from around the world shows that couplings between human and natural systems vary across space, time, and organisational units. They also exhibit nonlinear dynamics with thresholds, reciprocal feedback loops, time lags, resilience, heterogeneity, and surprises. Furthermore, past couplings have legacy effects on present conditions and future possibilities.

O'Connell (2005) set out some ideas and principles for modelling catchments as CHANS. A great deal of research has been carried out on the impacts of land use change on the hydrological functioning and responses of catchments, but these impacts have invariably been treated as passive. He advocated an active modelling approach to representing changes in which the agents of change (e.g. farmers and farm managers) respond to socio-economic drivers that determine land use patterns and management practices, and the use of social simulation techniques to represent human activities and decision-making. Monticino et al. (2007) describe such a CHANS modelling approach that couples natural system dynamics for a forest ecosystem to human land use decision-making, where the primary focus is on development decisions and their consequences. Interactions between human stakeholders are represented using multi-agent mod- els that act on forest landscape models in the form of land use change. Feedback on the effects of these actions is received through ecological habitat metrics and hydrological responses.

The use of ABM to model human activities and human decision-making in CHANS has received considerable attention in the literature, and there are some major challenges in this regard. Kurtz and Snowden (2003) list several challenges when seeking to capture the complex patterns of human behaviour in agent-based simulations, and in particular note that humans are not limited to (a) one identity or any common set of emotions; (b) acting in accordance with predetermined rules; or (c) acting on local patterns. Batten (2004) discusses one class of social systems - self-referential systems - that seems relatively immune from these problems. These relate to situations where the forecasts made by agents serve to create the world they are trying to forecast. The emergent complexity in these systems arises more from ways in which the agents interact and affect each other, and less from each agent's individual idiosyncrasies (Batten, 2004).

In discussing fairness principles in allocating water in Australia, Nancarrow and Syme (2004) note that the allocation, or re-allocation, of water to achieve environmental sustainability in farming communities can be a source of considerable conflict. They note that different stakeholders have different views of what constitutes fairness, and explore whether investigation of water allocation rules can contribute to gaining community consensus. They challenge the three basic assumptions of order, rational choice and intent in organisational decision support approaches, and observe that the Kurtz and Snowden (2003) discussion on the realities of contextual complexity and un-order epitomises the water allocation process they had analysed. By incorporating the justice criteria of stakeholders in different allocation rules, they suggest that ABM could be a useful decision support tool for assisting lay people to achieve social justice. In the context of flood risk, Vojinović and Abbott (2012) argue that social justice should underpin approaches to flood risk management, and integrate the human-social and the technological components to provide a holistic view.

An (2012) has carried out a comprehensive review of various decision models used in agent-based simulations of CHANS dynamics, discussing their strengths and weaknesses. Nine different modelling approaches are considered that range from more empirical to more process-based modelling approaches. An (2012) observes that humans make decisions in response to changing natural environments, which will in turn change the context for future decisions. Their abilities and aspirations for learning, adapting, and making changes may undergo evolution in their decision-making paradigm. Given all these features, An (2012) considers that it is "something that is still far away" to incorporate realistic reasoning about beliefs and preferences into understanding and modelling human decision-making processes (Ligtenberg et al., 2004). Without a more process-based 
understanding of human decision-making (e.g. the wayfinding process model of Raubal, 2001), An (2012) considers that it is very difficult to appreciate complexity at multiple dimensions or scales, and to achieve in-depth coupling of the natural and human systems. An (2012) concludes by advocating development of more process-based decision models as well as protocols or architectures that facilitate better modelling of human decisions in various CHANS. The challenges of modelling the human activities influencing decision-making in making flood protection investments are discussed in Sect. 6.

CHANS research has not yet established a significant presence in flood risk management research although, with the increasing focus on human and not just technical aspects of flood risk management noted in Sect. 2 above, it seems likely that this will happen. Di Baldassarre et al. (2013b) describe a very interesting, essentially CHANS approach, to conceptualising and modelling hydrological and social processes, and their complex interactions, in settled floodplains. They develop a simple, dynamic model to represent the interactions and feedback loops for hypothetical human-flood systems. The model, which is based on a set of four functional relationships, is then used to explore the dynamics of the humanflood system and the effect of changing individual characteristics, including external forcing such as technological development. The results show that the conceptual model is able to reproduce reciprocal effects between floods and people as well as the emergence of typical patterns. Grelot and Barreteau (2012) modelled population and vulnerability at the national scale in France as a test bed for evaluating the resilience of insurance scenarios to flood risk from extreme events. Brouwers and Boman (2011) implemented a flood risk management model as a basis for discussion of alternative policy strategies. The model, which integrates aspects of geographical, hydrological, economical, land use and social context, was used to assess the relationship between the role of the insurance industry and local government.

Taking a broader sustainable engineering perspective, Allenby (2000), in characterising the new paradigm of "Earth systems engineering and management" (ESEM), observes that managing the future evolution of tightly coupled human and natural systems will require the development of a capability to rationally "engineer" them through new management and engineering approaches that accommodate the balance between social, economic, and environmental capital. $\mathrm{He}$ represents this as the next great challenge for the engineering profession, and the new broader approaches to flood risk management under climatic and socio-economic change, and with a greater focus on humans, fall clearly within the scope of CHANS and ESEM.

The US National Science Foundation (NSF) has been funding the cross-cutting Dynamics of Coupled Natural and Human Systems (CNH) programme since 2001. Funded by NSF, the International Network of Research on Coupled Human and Natural Systems has been set up to foster interdisci- plinary collaboration in the field. Details of currently funded NSF projects are provided on the website (http://chans-net. org/). Most of the projects are focused on ecological systems, natural resource management and sustainability, and some intersect with hydrology.

\section{The natural system: stochastic flood model}

\subsection{Rationale}

As noted in Sect. 1, an overarching issue for flood investment strategies is the influence of global climate change on climatic and flood extremes. In the context of water resources management, Milly et al. (2008) suggest that, in assessing climate change impacts, the assumption of stationarity is no longer tenable, and that nonstationarity should be invoked. O'Connell and O'Donnell (2013) discuss the evidence for dismissing stationarity, and argue that, in the absence of clear and unequivocal evidence of nonstationarity that can be incorporated into modelling nonstationary hydrological variables, invoking nonstationarity presents somewhat intractable challenges. Rather, it would seem prudent to explore the limits of stationarity in the first instance, particularly in representing the long-term natural climatic variability that pre-existed global warming. By increasing the memory in a stationary stochastic model, the resulting increase in long-term variability can be indicative of the increased variability to be expected under global warming, and under which adaptation investment decisions will have to be made.

The traditional approach to making investment decisions in flood protection infrastructure is to estimate the probability distribution function (pdf) of annual maximum floods (AMFs) from the available data, to integrate the tail of the pdf with the damage function for the site at risk, and then to find the optimum design flood level that maximises the difference of discounted benefits and costs over the design life. The assumption of independence in AMFs underpins this approach. However, there is evidence that this assumption may be questionable when longer records of extreme rainfalls and floods are analysed. Ntegeka and Willems (2008) have identified multi-decadal variability in extreme rainfalls for a $100 \mathrm{yr}$ rainfall record in Belgium using a sliding-window method of analysis. Significant deviations in rainfall quantiles were found, which persisted for periods of 10 to $15 \mathrm{yr}$. In the winter and summer seasons, high extremes were clustered in the 1910s-1920s, the 1960s and recently in the 1990s. The authors note that this temporal clustering highlights the difficulty of attributing "change" in climate series to anthropogenically induced global warming. Intra- and multidecadal climatic variability in the United States has been linked to low-frequency variations in climatic state (Mauget, 2003a, b). Verdon and Franks (2006) comment that the instrumental record is insufficiently long to capture climate variability over multi-decadal timescales, and there is a need 
to augment observational records with palaeoclimate data to assess whether recent changes are abnormal.

Persistence/interannual variability in UK AMFs has been identified by Lane (2008), with clustering of floods in "floodrich" periods and few floods in "flood-poor" periods. Pattison and Lane (2012) have constructed and analysed a long flood record dating from 1770 for the River Eden in the UK and identified three main flood-rich periods: 1873-1904, 19231933, and 1994 onwards. Their analysis of climatic drivers suggests that systematic organisation of the North Atlantic climate system may be manifest as periods of elevated or reduced flood risk, and with major implications for analyses that assume that climatic drivers of flood risk either can be statistically stationary or are following a simple trend. Flood clustering in the United States has also been linked to climate teleconnection patterns (Villarini et al., 2013). However, it is not necessary to discard the assumptions of stationarity to model this interannual variability; there are stationary stochastic models that can reproduce this variability (Koutsoyiannis, 2011; O'Connell and O'Donnell, 2013; O'Connell et al., 2010a).

Periods that are flood-rich and flood-poor will be reflected in behaviours on investments by decision-makers. During flood-poor periods, encroachment on floodplains and the value of assets grow, while levels of investment decline; conversely, investment grows in flood-rich periods i.e. is reactive, as noted in Sect. 2 above. There is evidence of an "escalator effect" whereby progressively higher levels of flood defence are provided to protect against progressively increasing flood damage potential, caused mainly by post-defence development (Parker, 1995).

GCMs may not reproduce the observed low-frequency climatic variability (Johnson et al., 2011), so alternative approaches to climate risk assessment are needed (Brown and Wilby, 2012; Blöschl et al., 2013). In an exploratory study of climate risk assessment of adaptation strategies, proactive and reactive investment strategies were investigated under an increasingly variable climate exhibiting flood-rich and flood-poor periods (O'Connell et al., 2010a; O'Connell and O'Donnell, 2013). Following the approach of O'Connell (1971, 1974), a univariate autoregressive movingaverage (ARMA) $(1,1)$ model was used to represent increasing levels of long-term variability and persistence in simulated AMFs. A Monte Carlo sampling approach combined with a rational cost-benefit approach was used to evaluate proactive and reactive strategies for a single hypothetical site at risk from flooding. Here, this approach is extended to a hypothetical region with multiple sites at risk from flooding that are competing for limited funds available for investment in flood protection.

\subsection{Multi-site ARMA model}

A set of $N$ randomly distributed floodplain sites at risk from flooding is assumed for a hypothetical region with a domain size of $100 \mathrm{~km} \times 100 \mathrm{~km}$. The chosen area is arbitrary but broadly corresponds to the size of area under the jurisdiction of a regional flood and coastal committee in the UK; such committees have a key role in ensuring there are coherent plans for identifying, communicating and managing flood and coastal erosion risks across catchments and shorelines. No implicit linkages between the sites are assumed, other than through spatial correlation.

A multivariate ARMA $(1,1)$ model for annual maximum floods at the $N$ sites is assumed (O'Connell, 1974; Bras and Rodríguez-Iturbe, 1985); the model can be parameterised so that the level of persistence and interannual variability in AMFs can be controlled at each of the sites, so that the effect of this on investment strategies can be explored. The level of spatial coherence between the sites can also be controlled through a spatial correlation function, the parameters of which can also be varied to explore the sensitivity of investment decisions to spatial coherence. The distribution of annual maximum floods at each of the sites is assumed to be described by a three-parameter lognormal distribution with mean 1000 , standard deviation 400, and coefficient of skewness 1.5 (these can be varied across the sites to be more realistic, but were kept constant in the first instance to facilitate the interpretation of the results in Sect. 5). If $Y_{t}^{(i)}$ denotes a lognormal AMF variable at site $i$ with lower bound $a_{i}$, then the corresponding normal variable $X_{t}^{(i)}=\operatorname{Ln}\left(Y_{t}^{(i)}-a_{i}\right)$ will have mean $\mu_{x}^{(i)}$ and standard deviation $\sigma_{x}^{(i)}$. If $x_{t}^{(i)}=\left(X_{t}^{(i)}-\mu_{x}^{(i)}\right) / \sigma_{x}^{(i)}$, then a multivariate normal ARMA $(1,1)$ model with mean zero and unit standard deviation at each site can be written as

$\boldsymbol{x}_{\mathbf{t}}=\mathbf{A} \boldsymbol{x}_{t-1}+\mathbf{B} \boldsymbol{\varepsilon}_{t}-\mathbf{C} \boldsymbol{\varepsilon}_{t-1}$,

where $\boldsymbol{x}_{t}$ and $\boldsymbol{x}_{t-1}$ are $(N \times 1)$ vectors with elements $x_{t}^{(i)}$ and $x_{t-1}^{(i)}$, respectively; $\boldsymbol{\varepsilon}_{t}$ and $\boldsymbol{\varepsilon}_{t-1}$ are vectors of $N(0,1)$ independent normal random variables; and $\mathbf{A}, \mathbf{B}$, and $\mathbf{C}$ are $(N \times N)$ matrices of coefficients that are defined from $\mathbf{M}_{0}, \mathbf{M}_{1}$, and $\mathbf{M}_{2}$, the lag zero, lag one and lag two cross-correlation matrices.

If the matrix $\mathbf{A}$ is assumed to have a diagonal form with all diagonal elements predefined and equal to $\varphi$, the autoregressive parameter of a univariate ARMA $(1,1)$ model, then the following relationships can be used to solve for the matrices $\mathbf{B}$ and $\mathbf{C}$ :

$$
\begin{aligned}
& \mathbf{B}+\mathbf{C}=(\mathbf{I}+\mathbf{A}) \mathbf{M}_{0}(\mathbf{I}+\mathbf{A})^{T}-\mathbf{M}_{1}(\mathbf{I}+\mathbf{A})^{T} \\
& \quad-(\mathbf{I}+\mathbf{A}) \mathbf{M}_{1}^{T}=\beta \beta^{T} \\
& \mathbf{B}-\mathbf{C}=(\mathbf{I}-\mathbf{A}) \mathbf{M}_{0}(\mathbf{I}-\mathbf{A})^{T}+\mathbf{M}_{1}(\mathbf{I}-\mathbf{A})^{T} \\
& \quad+(\mathbf{I}-\mathbf{A}) \mathbf{M}_{1}^{T}=\gamma \gamma^{T} .
\end{aligned}
$$

Without loss of generality, a lower diagonal form can be assumed for the matrices $\mathbf{B}$ and $\mathbf{C}$, and Eqs. (2) and (3) can then be solved for the elements of $\mathbf{B}$ and $\mathbf{C}$. As the matrix $\mathbf{A}$ has been predefined, the matrix $\mathbf{M}_{2}$ is not required 

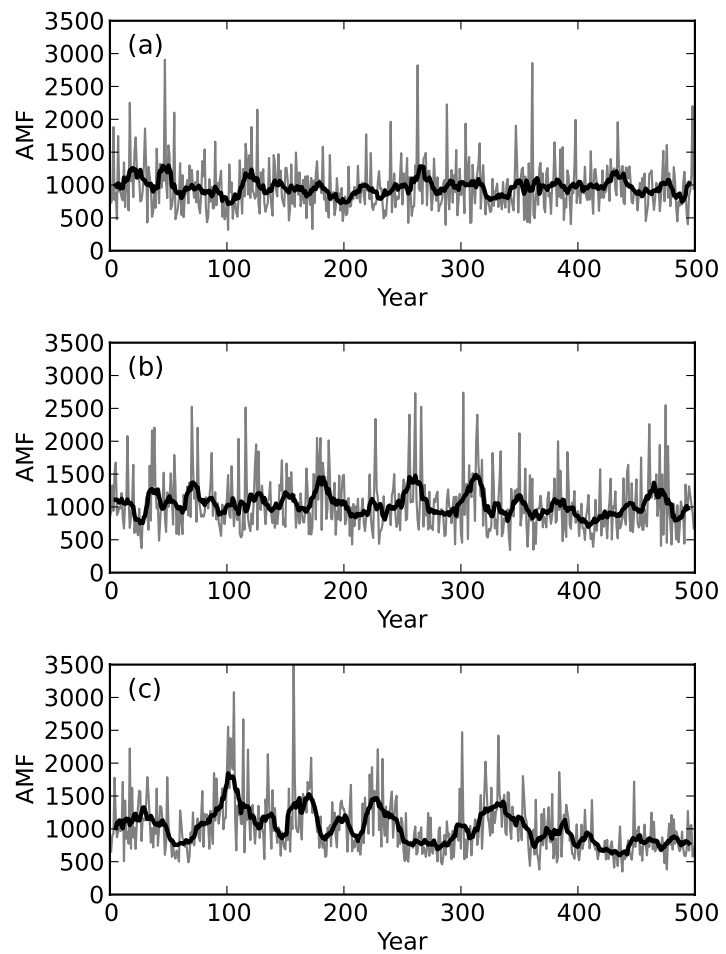

Fig. 1. Example realisations of AMF series for a single site generated using an ARMA $(1,1)$ model, where (a) is an independently and identically distributed AMF series with no persistence $(\varphi=\theta=0)$; (b) is for a moderate level of persistence, $\varphi=0.95$ and $\rho=0.1$; and (c) is for a high level of persistence, $\varphi=0.95$ and $\rho=0.3$. The $11 \mathrm{yr}$ moving average is superimposed in bold.

to solve for $\mathbf{A}$ ( $=\mathbf{M}_{2} \mathbf{M}_{1}^{-1}$ otherwise). With this definition of $\mathbf{A}$, the parameter $\varphi$, together with the lag-one serial correlation $\rho$, can be used to control the level of persistence at each site; both are kept constant here across sites. As $\varphi$ approaches the upper stationarity boundary of 1 , the level of persistence/interannual variability increases, with increasingly extended flood-rich and flood-poor periods. The elements of the matrix $\mathbf{M}_{0}$ are filled using the spatial correlation function and the distance between the sites; an exponential isotropic correlation function was used with a rate of decay based, as a guideline, on the observed dependence between extreme sea surge, river flow and precipitation data in eastern Britain (Svensson and Jones, 2002). If $\rho_{i j}(0)$ denotes an element of the matrix $\mathbf{M}_{0}, i, j=1,2, \ldots N$, then the elements of $\mathbf{M}_{1}$ are specified as $\rho \rho_{i j}(0)$, based on the diagonal specification for the matrix $\mathbf{A}$. The matrices $\mathbf{B}$ and $\mathbf{C}$ can then be solved for using Eqs. (4.2) and (4.3).

Example realisations of AMFs are shown in Fig. 1 for a single site, where (a) is an independently and identically distributed AMF series with no persistence; (b) is for a moderate level of persistence corresponding to $\varphi=0.95$ and lagone serial correlation $\rho=0.1$, and (c) is for a high level of persistence corresponding to $\varphi=0.95$ and lag-one serial cor- relation $\rho=0.3$. Note that for any given $\varphi, \theta$ can be defined to give the required value of $\rho$.

\section{Rational flood protection investment within the coupled human and natural system}

\subsection{Evaluation of investment strategies using cost-benefit analysis}

Given its use by many governmental agencies in assessing the economic viability of proposed flood defence projects (e.g. HM Treasury, 2011), cost-benefit analysis (CBA) provides a useful starting point for the comparison of alternate investment strategies in an increasingly variable climate. The approach taken here involves identifying the level of investment in flood defences that maximises the net benefits through the use of the objective function

$\mathrm{NPV}=\sum_{t=1}^{n}\left[1 /(1+r)^{t}\left(\mathrm{EAD}_{t, \mathrm{CU}}-\mathrm{EAD}_{t, \mathrm{IMP}}-\operatorname{cost}_{t}\right)\right]$,

where NVP is the net present value; $\mathrm{EAD}_{t, \mathrm{CU}}$ is the expected annual damage corresponding to the current level of protection (i.e. a do-nothing strategy); $\mathrm{EAD}_{t, \mathrm{IMP}}$ is the expected annual damage corresponding to the improved level of protection (to be obtained by optimising NVP); and $\operatorname{cost}_{t}$ is the level of investment. The discount rate, $r$, is used to discount future damages and costs back to the present value, with a high rate placing more weight on benefits gained in earlier periods. The UK Treasury suggests a time-varying discount rate starting at $3.5 \%$, and declining to $2.5 \%$ after $75 \mathrm{yr}(\mathrm{HM}$ Treasury, 2011). $\mathrm{EAD}_{t, \mathrm{CU}}$ and $\mathrm{EAD}_{t, \mathrm{IMP}}$ are obtained by integrating a damage function with the tail of the pdf, Fig. 2. The shape of the damage function was chosen so that a large amount of damage occurs with initial overtopping, reflecting substantial development on the floodplain, and the cost function comprises an initial cost and a linear proportional cost. The cost and damage functions shown in Fig. 2 have the same monetary units, but as this is a hypothetical case the values are just indicative.

Hence, the natural system, represented by AMF floods, is coupled to the human system (the floodplain residents) through the interaction created by investments in flood protection infrastructure, and associated costs and economic damage. A more people-centred approach is presented in Sect. 6 in which a framework is outlined for modelling the human activities that drive flood protection investment.

\subsection{Investment strategies}

Two alternate investment strategies were evaluated: (a) a proactive strategy where an existing level of flood protection (corresponding to a return period of $50 \mathrm{yr}$ ) is upgraded at all sites at the beginning of the design life, and (b) a reactive strategy in which investment is made only when the existing flood protection is exceeded at a site. 


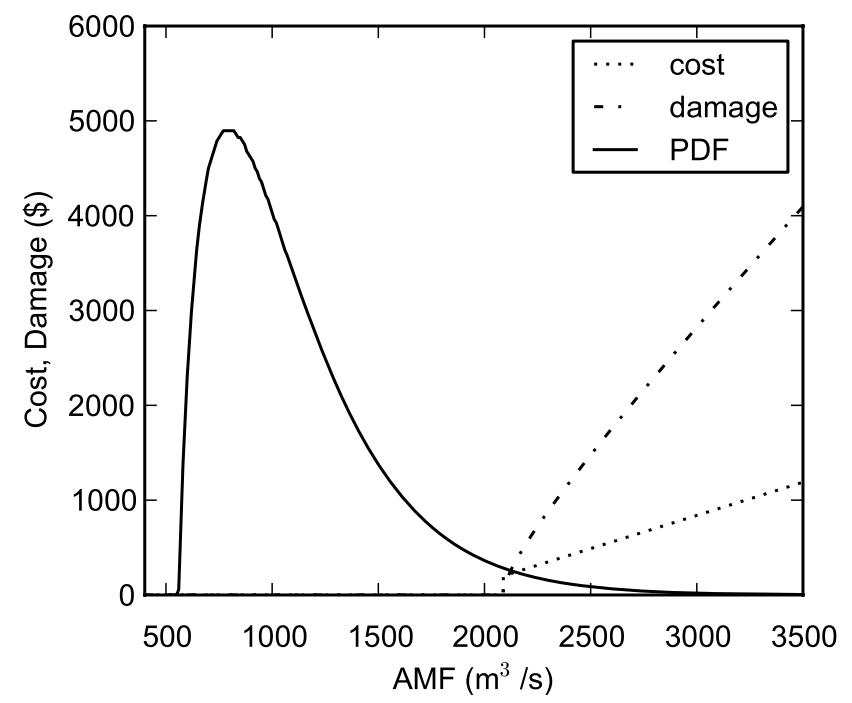

Fig. 2. Schematic of pdf of annual maxima floods, cost function and damage function.

A Monte Carlo approach was used to evaluate the two investment strategies. For each of the 10 sites, an ensemble of $50000150 \mathrm{yr}$ realisations was generated for the IID (independently and identically distributed), moderate-persistence $(\varphi=0.95, \rho=0.1)$ and high-persistence $(\varphi=0.95, \rho=$ 0.3 ) levels. Each realisation was separated into a $50 \mathrm{yr}$ "historic record" and a subsequent $100 \mathrm{yr}$ "design life" period. The choice of a $50 \mathrm{yr}$ historical record was based on the typical length of flow records at gauged sites in the UK (Jones et al., 2006), and the $100 \mathrm{yr}$ design life was based on the recommended appraisal period for flood risk management plans in the UK (Defra, 2009).

In the case of the proactive strategy, the pdf of the AMFs was estimated from the historic record by fitting a lognormal distribution using L-moments (Hosking and Wallis, 1997). For the reactive strategy $50+n_{r}$ years of data were used to estimate the pdf, where $n_{r}$ is the number of years in the design life before the existing level of protection is exceeded (Fig. 3). The pdf was combined with a damage function to estimate the expected annual damage for the current situation $\left(\mathrm{EAD}_{\mathrm{CU}}\right)$, and then the optimal level of protection was determined using the cost-benefit function (Fig. 2 and Eq. 4). The performance of each strategy was assessed by calculating the actual damage during the design life accumulated over the 10 sites.

An additional set of simulations was performed for each strategy in which full knowledge of the population AMF pdf was assumed in each case. This will obviously impact on the calculation of the expected annual damage for both the current and improved situations, and provides a reference point corresponding to perfect information on the pdf.

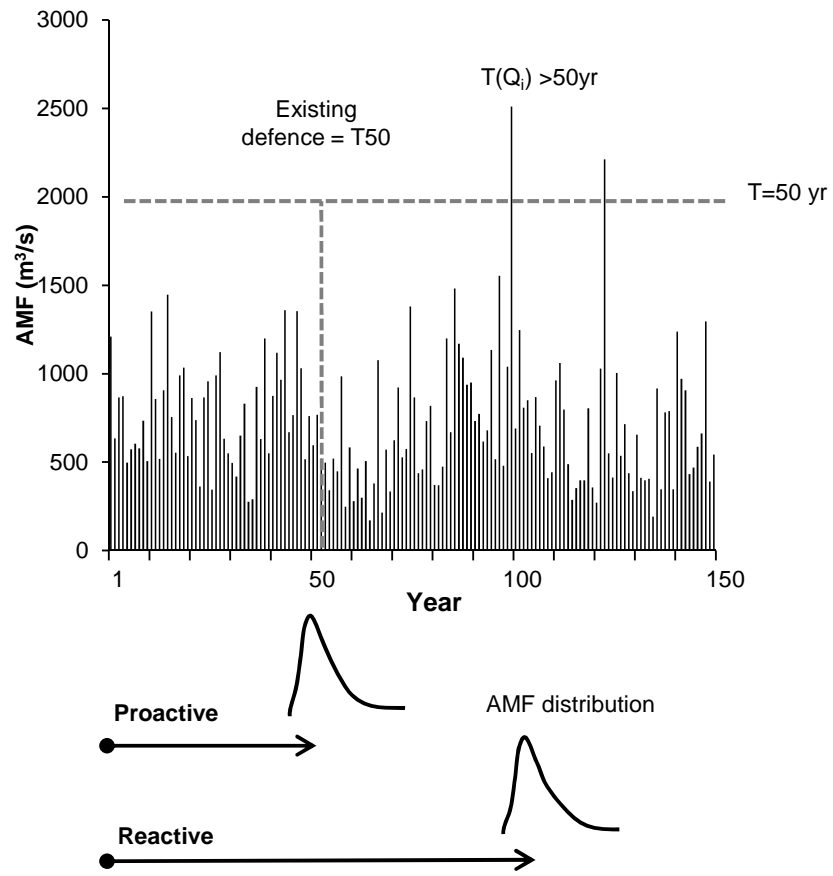

Fig. 3. Typical realisation of "historic record" (50 yr) and "design life" (100 yr). An exceedance of the current level of protection takes place around $n_{r}=50 \mathrm{yr}$, so $50+n_{r}$ years of data are available to estimate the pdf of annual maximum floods for the reactive case.

\subsection{Results}

The discounted net benefits (reduction in damage minus costs) are shown for the IID case, the moderate-persistence and high-persistence cases in Fig. 4. The values are the average over the 50000 realisations across all 10 sites. In the proactive case the net benefits are similar for all persistence levels, although as expected there is a significant advantage in using the population rather than the sample statistics. Where full knowledge of the population is assumed, the optimal level of investment is known precisely, which corresponds roughly to the $150 \mathrm{yr}$ flood. Where the pdf is estimated from the historical record, the effect of persistence influences the cost-benefit analysis in determining the level of protection, but the average net benefit taken over 50000 realisations is similar for all levels of persistence.

When using the population pdf statistics, proactive investment is best, as the net benefits are higher than those for the reactive case. In the reactive case, investment is only made after the first flood exceeding $Q_{50}$, and hence there is an initial damage prior to improvement in defences. Of greatest interest in the reactive case is the increase in net benefits as the persistence increases, with the reactive strategy performing better than the proactive strategy under high persistence when the sample statistics are used; i.e. there is a crossover from proactive to reactive as the best strategy. These results 

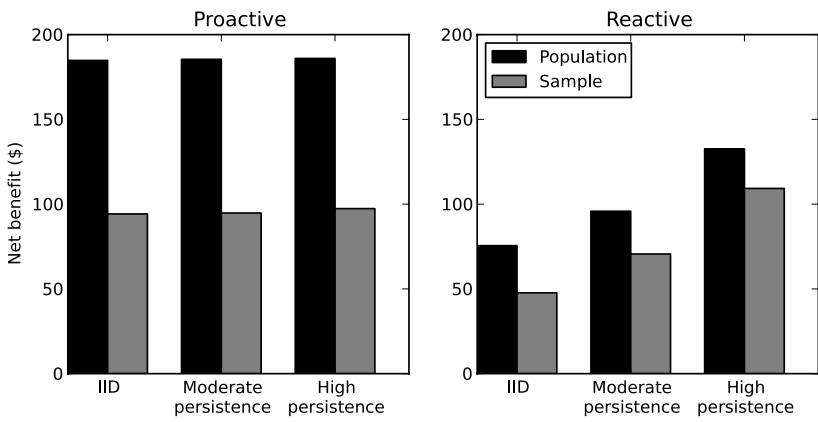

Fig. 4. Comparison of net benefits for the proactive (left panel) and reactive (right panel) cases.

can be explained by examining the frequency of flooding and damages in greater detail.

The percentage of $100 \mathrm{yr}$ AMF records in which no flood exceeded the current level of protection was $13 \%$ in the IID case (which is as expected given the relationship $P=$ $1-(1-1 / T)^{n}$, where $n=100$ and $\left.T=50\right)$ and $27 \%$ in the high-persistence case. This means that in the reactive case with high persistence, no investment is made at a larger number of sites, reducing the average cost across all realisations, and increasing the net benefits

Results do depend upon the choice of the cost and damage functions, as well as the assumed discount rate and the lengths of the historic and design periods. A limited number of sensitivity runs were performed in which the parameterisation of the cost and damage functions were modified. It was found that the proactive strategy always outperformed the reactive strategy for the IID case. The choice of optimal strategy was less clear in the high-persistence case. As the return period associated with the optimised level of protection increased, the proactive strategy became more favourable. Additional exploration of these sensitivities will be performed in future work.

\subsection{Limitations of cost-benefit analysis}

It should be noted that there are a number of difficulties in the application of cost-benefit analysis. These include quantifying the economic cost of flood damage (Merz et al., 2010), the pricing of human welfare and the ecosystems impacted by development (Ackerman et al., 2009), and predicting the actions individuals and societies will take in the future. Trust in authorities, and cultural and individual factors play important roles in determining the willingness of individuals to invest in risk preparedness and take risk mitigation actions (Wachinger et al., 2013; Eiser et al., 2012; Scolobig et al., 2012). Additionally, the building of defences changes the perception of flood risk, potentially leading to increased development in floodplain areas, which is difficult to predict over long time horizons (Di Baldassarre et al., 2013a). However, perhaps the major limitation of the above analysis is

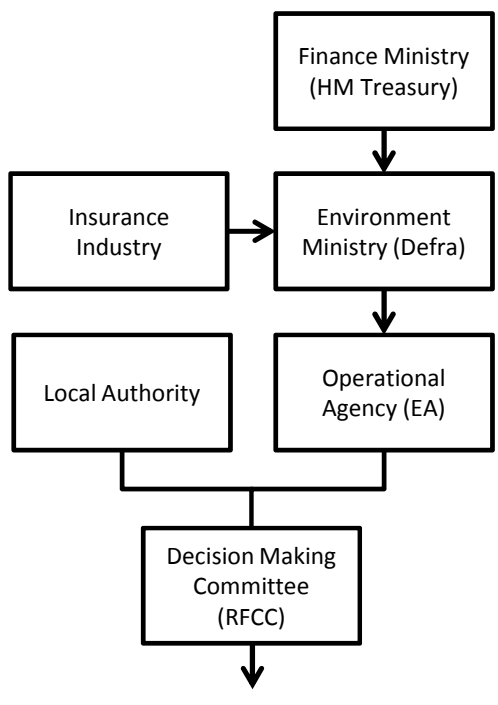

Local investment decision

Fig. 5. Institutional actors in the decision-making process.

that only cost-benefit analysis was used in policy appraisal. The role of cost-benefit analysis, which has its origins in investment appraisal, is but one component of policy making (Pearce, 1998). A sustainable approach to flood risk management must embrace economic, environmental and social objectives, resolving the conflicts that arise, and consider the new behavioural patterns and social processes that emerge. In this regard, agent-based modelling has the potential to describe this complexity in the decision-making process, as discussed below.

\section{The human system: towards agent-based modelling of human activity affecting flood investment decision- making}

An agent-based modelling (ABM) framework is being developed in conjunction with the regional ARMA natural system AMF model presented in Sect. 4 to explore the decision-making process for flood investment at the regional level within this coupled human and natural system. This work draws upon experience of institutional-citizen interplay studies conducted throughout the UK, and the wider agent-based modelling literature. The primary aim is to provide insight into how communities respond to actual flooding, and whether this influences the funding of flood protection. Firstly, the institutional actors are introduced, and then their interaction with floodplain communities within an agent-based context is presented. 


\subsection{Institutional actors involved in the decision-making process}

The main institutional actors in the decision-making process for FRM are shown in Fig. 5. An English perspective is used in the following, but many of the roles of actors and feedbacks between them have parallels in many Europeans countries. The US approach differs from that in Europe in that preparation, response and recovery dominate over prevention (ten Brinke et al., 2008).

\subsubsection{Central government}

The institutional framework for flood management in England is fragmented with the environment ministry (Defra) responsible for policy-making and the Environment Agency (EA) for operational responsibility. Defra's role is constrained by the economically orientated Treasury, which controls public financial resources and sets the principles of public-sector financial operations (Krieger, 2013). As a result of this relationship that is based on financial accountability, FRM historically has relied primarily on a project level riskbased cost-benefit ratio as a basis for investment, although recent reforms have strengthened the social and environmental dimensions (Johnson et al., 2007). It is interesting to contrast the UK and German models, with the latter aiming to provide a similar level of protection to the population at risk through the adoption of the $100 \mathrm{yr}$ flood level (HQ100) standard (Krieger, 2012).

\subsubsection{Operating authority}

Defra provides priority-defined guidance to the operating authority (EA) to prevent flood protection projects entering the funding process unless they achieve some economic, social and environmental performance levels (Johnson et al., 2007). However, the EA is a quasi-independent agent of the government with laws giving only permissive powers rather than duties (Harries and Penning-Rowsell, 2011). Thus, the organisation has a degree of autonomy on how to spend the annual budget it receives from Defra. Additionally, there is devolved power within the EA, with local staff left some discretion about the design and content of the proposals that they put forward to the decision-making committees.

\subsubsection{Regional flood and coastal committees}

Regional flood and coastal committees (RFCCs), a requirement of the Flood and Water Management Act 2010, are central to achieving the government's new partnership funding approach (Defra, 2011). These committees can raise a local levy to reduce the cost of projects to the national tax payer, thereby bringing forward scheme delivery, or to fund schemes that satisfy local strategy. The aim is to provide communities with choice and provide localism to decisionmaking (Defra, 2011). RFCCs also provide for local demo- cratic input through the majority local authority membership (Defra/EA, 2011).

\subsubsection{Local authorities and land use planning}

Autonomous, directly elected local authorities have traditionally had a major control over land use/development decisions, which has caused tension with the EA to whom blame is attributed in times of flood disasters. However, the recent UK Government's Planning Policy Statement 25 (PPS 25) requires recognition of flood risk and climate change projections in development appraisal, strengthening the role of the EA. This involves avoiding new development plans in high flood risk areas and ensuring that flood risk is adequately addressed in planning appraisal. PPS 25 has additionally spread the risk towards those that are benefitting from development within flood-prone areas, with developers required to implement flood alleviation measures. However, there remains a tension as government policy strongly favours the redevelopment of brownfield land, much of which lies in areas at risk of flooding (Porter and Demeritt, 2012).

\subsubsection{Insurance}

Flood insurance provision in the UK is based on the "Statement of Principles" between the government and the Association of British Insurers (ABI), which guarantees existing customers access to home insurance in flood risk areas. (This agreement will expire in 2013). UK flood insurance provision is unusual in Europe in that risk is reflected in premiums paid by individual households, although there is a subsidy from low- to high-risk households. There is a concern that, if left to the market, there will be differentiation between households at different levels of risk which may leave many lowincome households effectively uninsurable, leading to social blight (O'Neill and O'Neill, 2012).

\subsection{Influence of community responses on the decision-making process}

The above discussion demonstrates that institutional responsibilities for managing flood risk are fragmented, with the institutions involved having a degree of autonomy. This means that there is some regional flexibility in the provision of flood protection. For example, the EA has been historically reactive and responsive to flood events that have stimulated public demand for defences (Harries and Penning-Rowsell, 2011). The powers imparted to the RFCCs, with the inclusion of local authority members, has the potential to increase the influence of community action in gaining flood protection. 


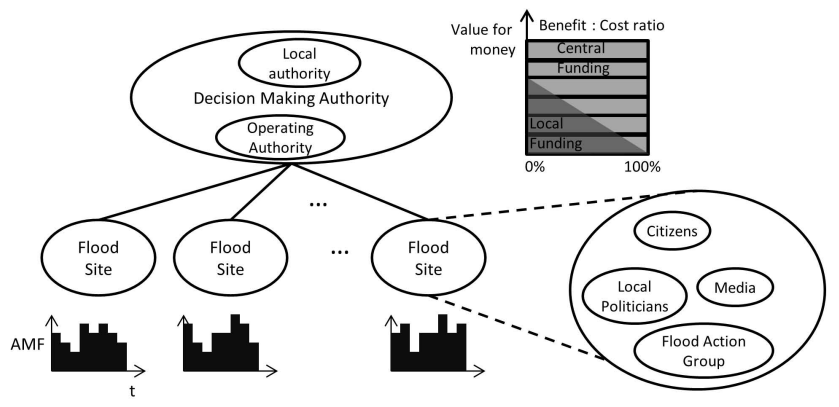

Fig. 6. Schematic of ABM framework for regional decision-making. The box is a simplified representation of the UK partnership funding scheme, where those projects with the highest benefit-to-cost ratios receive $100 \%$ central funding, with others requiring a local funding contribution to proceed.

\subsubsection{ABM framework}

Before commencing to describe an exploratory $\mathrm{ABM}$ framework that might encompass the above human decision-making process in greater detail than the somewhat outdated cost-benefit approach, it is appropriate to highlight some key aspects of the methodology, including limitations. ABMs are often criticised for a lack of verification, calibration and validation. The proposed model is not to be used in predictive mode, but rather to explore futures in which there is deep uncertainty. Under such situations accurate predictions are not possible (Lempert, 2002; Bankes, 2002). However, given that ABMs correspond quite closely to the ways that individual stakeholders generally think about actions and interactions, there is the potential for model appraisal, and for actors/stakeholders to gain insight into the decision-making process that they seek to influence. A model can be deemed useful if stakeholders view it as plausible and it enables them to explore the consequences of actions that they may wish to undertake (Moss et al., 2001). Such participatory agentbased simulation has proved useful in exploring the achievement of policy objectives with stakeholders (e.g. Downing et al., 2001; Becu et al., 2003).

In designing an $\mathrm{ABM}$, there is a tension between the perceived need to represent the human system decision-making problem domain in as rich a manner as possible, while retaining simplicity. There is a risk that richness will introduce multiple complexities that will obscure the significance of the model. Simpler models are often preferable, as the data requirements are more manageable and they can be described and understood (Pellizzari, 2005; Crooks et al., 2008), which is particularly important if a participatory approach is used. However, ambiguity remains over the specification of agents' motivations, interactions and beliefs.

A schematic of the proposed ABM framework is provided in Fig. 6, which is an abstraction of the institutional relationships described above that operate at the regional level. The natural system is represented using the ARMA AMF model (Sect. 4), in which the level of persistence can be varied to create clusters of floods in the AMF series. This controls the timing and extent of flooding in a given number of virtual cities (sites) at risk from flooding. The "memory" in the ARMA model is imparted to the community, not only in terms of greater demands for protection in flood-rich periods but also in terms of the citizens' flood memory and emotional intensity. If sufficiently motivated, the citizens in the community will form pressure forums, flood action groups, and generate media attention. Both in the UK and Europe, there is a public perception that managing flood risk is a public rather than private matter (Lara et al., 2010; Kellens et al., 2013); hence, pressure is placed on elected officials, who influence local authority decision-making. Ultimately, if sufficient, this pressure will influence the decision-making authority, which comprises local authority members and the operating authority (e.g. the EA). There is a need to assess whether "event-driven" responses provide good decisionmaking and good value for public money, and whether those with weak representation lose out (Naess et al., 2005; Parliamentary Select Committee, 2013).

A primary reason for selecting an agent-based approach is the ability to model the actions and interactions of the individual decision-making entities; hence the groupings in Fig. 6 must typically represent many agents. For example, a virtual city requires a spatial representation of the areas in which the citizens reside to allow representation of the social interactions that are important in group activity and mobilisation (e.g. DeMarzo et al., 2003).

\subsubsection{Community responses}

There is a need to explore the motivations and competence of the citizen agents involved and how hierarchical relationships are formed, and whether this impacts on the funding process. Citizen agents can be broadly divided into the following categories:

- influentials, who have strong motivation and competence;

- reluctants, who do not accept that their property is at risk, which may be explained in terms of economic interests (insurance) and the psychologically unsettling nature of accepting risk (Burningham et al., 2008; Cashman, 2009; Grothmann and Reusswig, 2006), or fear of the loss of aesthetics (Whatmore and Landström, 2011);

- others, whose opinions may be swayed by the views of their social networks.

Influentials are important agents in the formation of flood action groups, which are the key pressure groups involved in mobilising community outrage, and media attention after a flood event. For example, following the 2008 flood which impacted upon 1000 properties in the town of Morpeth in 
North East England, there were calls that "It must never happen again!" Additionally, there were demands for action "to lobby councillors, push our MPs to keep the issues before parliament and press the Environment Agency to bring forward their plans for flood alleviation". There is a significant body of agent-based literature exploring the role of influentials (e.g. Deffuant et al., 2002; DeMarzo et al., 2003) and how social relationships influence the shaping of a community's views (e.g. Gulati et al., 2011; Hamill and Gilbert, 2009).

Politicians are assumed to be primarily motivated by maintaining or gaining power, which can be achieved by gaining public support through their actions. The national politician (member of parliament: MP) representing the community of Morpeth spoke in parliament seeking government support to help to rebuild the town and "to prevent a similar occurrence". It was also argued that an improved flood defence scheme would release valuable riverside land for redevelopment. This raises questions regarding a community's acceptance of policies such as Making Space for Water and the viability of future land use planning to reduce risk. Cashman (2009) describes the politicising of a flood event at a time approaching a local election, despite the absence of political involvement after an event several years previously. The role of the strength of a community's flood memory and how this can result in a single electoral issue are therefore important aspects (DeMarzo et al., 2003; McEwen et al., 2012a).

Use of the media is an important method that can be utilised by a community in gaining support, both within their own community and regionally. Following the devastating flood in Hull in 2007, local residents and councillors were unhappy at the lack of media coverage. It was believed that certain communities geographically closer to the centre of power are given preference, with Hull dubbed by the lead councillor "the forgotten city" (Kim et al., 2012). Alternatively, a regional newspaper used the headline "Sick of sandbags and sympathy" to highlight the angry reaction to flooding in Belford, UK (Wilkinson et al., 2010). This village subsequently received local financial support for flood alleviation measures.

The above aspects will influence public consultation exercises which are held with members of the public and the decision-making authority. Local decision-makers may perceive those that are most vocal as the public to whom they are responsible (Irvin and Stansbury, 2004). Consequently, national level policies may not be met, with a distortion of the decision-making process in which recent flood victim views are paramount and have an appeal beyond a rational costbenefit approach (Harries and Penning-Rowsell, 2011). In times of flood crises, there will be multiple demands for flood protection from several communities, which can be viewed as an auction for protective measures, in which the outrage a community generates becomes the principle currency.

\subsection{Human activity at the catchment scale}

The focus of the framework is to provide an understanding of the motivations, actions and influence of citizens and institutions on the delivery of flood protection investment within cities. However, societies also impact on catchment hydrology, for example through changes in upstream rural land use and water management (e.g. Brath et al., 2006), thereby changing the frequency and magnitude of the "natural" flood-magnitude relationship. Also, engineered flood defences in priority areas may have downstream impacts (Di Baldassarre et al., 2009). However, evidence for land use change impacts in flood records can be difficult to identify in the presence of significant natural climatic and hydrological variability (Geris et al., 2013; Robson et al., 1998; O'Connell et al., 2007), and so the latter has been the main focus here in representing the natural system.

The proposed framework is ambitious, and the complexity of representing additional societal interactions with the natural system, many of which are poorly understood, remains a future challenge. For example, although agent-based land use models are widely used in the research community (Matthews et al., 2007), understanding and quantifying the impacts of changes in land use on hydrology remains a major challenge and may need the inclusion of additional actors, e.g. national or EU agricultural policy (Matthews et al., 2007; Hall et al., 2003; O'Connell et al., 2010b). Perhaps a more realistic aim would be to incorporate how improvements in flood protection affect the future urban spatial dynamics, which is an area that has received attention from the agent-based modelling community (Filatova et al., 2011; Irwin, 2010).

\subsection{Contrasting the cost-benefit and agent-based modelling approaches}

The traditional cost-benefit method of determining flood defence investments reflects a top-down approach in which decisions have historically been made on behalf of society by a government agency. However, the modern approach to flood risk management is, as already noted, evolving into a peoplecentric approach in which multiple actors interact in a complex social milieu to secure investment funds that will reduce the risk to themselves and their property. As already discussed above, modelling the investment process under these conditions presents a major challenge. Agent-based modelling represents a possible approach to tackling this challenge, and offers the prospect of making the decision-making process more transparent and participative for stakeholders. The limitations of cost-benefit analysis have been discussed in Sect. 5 above, particularly the difficulty of incorporating social and environmental costs and benefits into $\mathrm{CB}$ analysis. Nonetheless, CB analysis is likely to continue to be regarded as a norm for demonstrating that investments in public-sector infrastructure projects are providing value for money. 


\section{Discussion, conclusions and further work}

With the prospect that flood hazard may increase in the coming decades due to global warming, there is a need for methodologies for evaluating adaptation strategies under increasingly variable climates. It is advocated here that, since clear and unequivocal evidence has yet to emerge for quantifiable sources of nonstationarity in flood records, the limits of stationarity should first be explored in assessing the performance of flood protection investment strategies.

To provide insight into how we may deal with flood protection investment under an uncertain future, rational costbenefit analysis coupled with Monte Carlo simulation of annual maximum floods (AMFs) has been used to explore the performance of proactive and reactive investment strategies for flood protection. A stationary stochastic model capable of representing increasingly variable climates has been used to create AMF series at a number of virtual city sites lying within a region. Firstly, it was found that, irrespective of the level of persistence and the investment strategy taken, it is difficult to make good decisions with the short historic records $(\sim 50$ yr $)$ that are typically available to engineering hydrologists. Secondly, it was found that, while a proactive strategy performed best for IID and low-persistence AMF floods, the reactive "wait and see" strategy outperformed the proactive strategy, in terms of net benefits delivered, at very high levels of persistence. This demonstrates that the call for proactive investment to combat the impacts of an increasingly variable climate may be premature, given that natural climatic variability has been manifested in the past through flood-rich and flood-poor periods.

In practice, decision-making at a regional or national level is never simply reactive or proactive. In the UK, a proactive case is taken for cities that are of greatest importance to the national economy (Lavery and Donovan, 2005), with a more reactive approach taken elsewhere. Additionally, although cost-benefit analysis plays an important role in prioritising those sites that receive protection, the more holistic approaches that are now being taken to flood risk management (FRM) encompass environmental, social and economic objectives, as well as widening stakeholder participation. Decision-making now encompasses multiple objectives and multiple stakeholders, and flood risk management is becoming increasingly people-centred. While there is an expanding literature on the social science aspects of flood risk management - such as institutional structures and responses, building flood resilience at the community level, and social justice aspects - there is an evident paradigm lock between the quantitative technical aspects of FRM and the more qualitative treatment of the social science aspects. It is therefore difficult to quantify how the social dimensions of FRM bear upon decisions relating to flood protection investments. It is suggested that coupled human and natural system (CHANS) modelling, which has developed primarily in the ecological modelling field, offers a framework for integrating the social and technical aspects, with agent-based modelling (ABM) providing a basis for modelling the human activities of multiple stakeholders that influence decision-making.

Developing an ABM framework to describe the complexity of decision-making in CHANS modelling is a major challenge. However, meeting this goal would help in gaining an understanding of whether policy initiatives such as Making Space for Water can be effectively delivered, and the implications for social justice (Johnson et al., 2007) as well as delivering value for money for investments in the traditional economic sense. By coupling the ABM model to the natural system AMF model, and quantifying the costs and damages that ensue from decision-making in flood-rich and flood-poor realisations that emerge from the CHANS model, the value for money that results can be assessed, and compared with what emerges from proactive and reactive strategies determined using rational cost-benefit analysis. Moreover, community action groups will have an opportunity to view the consequences of their activities in securing prioritisation of investments, on the availability of funding for investment elsewhere, and on the wider implications for equity and social justice.

Based on a review of the main actors/stakeholders that currently influence decisions on flood investments in the UK, an ABM modelling framework has been outlined. Current work is exploring how this can be implemented, bearing in mind some of the known limitations of ABM. Future work will explore how an $A B M$ representation of decision-making can play out in terms of investments in the virtual region considered above, and what the value for money and social justice consequences can be. In the first instance, selected floodrich and flood-poor realisations from the multivariate ARMA $(1,1)$ model will be used to gain insight into how the coupling between the human and natural systems affects investments as the level of persistence/interannual variability increases. Moreover, the influence of the different aspects of memory within CHANS models of flood protection investment and other FRM responses (e.g. building resilience) will be explored. Firstly, there is the long memory in the natural climate system (Mesa et al., 2012; Fraedrich et al., 2009) which is on decadal/centennial/millennial scales, and which is represented here using a stationary ARMA $(1,1)$ model. Secondly, there is the institutional/stakeholder memory of past floods which decays in flood-poor epochs, and which influences floodplain encroachment and the allocation of government funds for investments. The need for "sustainable memory" (McEwen et al., 2012b) has been noted above. Thirdly, flood protection infrastructure has memory (C. G. Kilsby, personal communication, 2013), as its effectiveness decays over time, and repeated loadings in flood-rich periods can lead to failure and greatly increased damage (Dyer, 2004; Dawson et al., 2005). It is therefore evident that CHANS modelling of flood protection investments and flood risk management in the current people-centred approaches, and under the pressures of global climate and socio-economic 
change, offers exciting possibilities for developing the new paradigm of socio-hydrology.

Acknowledgements. This research was supported by the EPSRC Grants "Earth Systems Engineering: Sustainable systems engineering for adapting to global change" (EP/G013403/1) and "Flood MEMORY: Multi-Event Modelling Of Risk \& Recovery" (EP/K013513/1). We thank Giuliano Di Baldassarre and 2 anonymous reviewers for their constructive comments which have helped improve this manuscript.

Edited by: M. Sivapalan

\section{References}

Ackerman, F., DeCanio, S. J., Howarth, R. B., and Sheeran, K.: Limitations of integrated assessment models of climate change, Clim. Change, 95, 297-315, 2009.

Allenby, B.: Earth systems engineering and management, Technology and Society Magazine, IEEE, 19, 10-24, doi:10.1109/44.890078, 2000.

An, L.: Modeling human decisions in coupled human and natural systems: Review of agent-based models, Ecol. Modell., 229, 2536, 2012.

Bankes, S. C.: Tools and techniques for developing policies for complex and uncertain systems, Proc. Natl. Acad. Sci. USA, 99, 7263-7266, 2002.

Barredo, J. I.: Normalised flood losses in Europe: 1970-2006, Nat. Hazards Earth Syst. Sci., 9, 97-104, doi:10.5194/nhess-9-972009, 2009.

Batten, D. F.: Simulating human behaviour: the invisible choreography of self-referential systems, The International Environmental Modelling \& Software Society (IEMSS) Conference, Osnabrück, Germany, 14-17 June, 203-208, 2004.

Becu, N., Perez, P., Walker, A., Barreteau, O., and Page, C. L.: Agent based simulation of a small catchment water management in northern Thailand: Description of the CATCHSCAPE model, Ecol. Modell., 170, 319-331, 2003.

Blöschl, G., Viglione, A., and Montanari, A.: Emerging Approaches to Hydrological Risk Management in a Changing World, in: Climate Vulnerability: Understanding and Addressing Threats to Essential Resources, edited by: Pielke, R., Elsevier, Vol 5, 3-10, 2013.

Bras, R. L. and Rodríguez-Iturbe, I.: Random Functions and Hydrology, Dover Publications, New York, 559 pp., 1985.

Brath, A., Montanari, A., and Moretti, G.: Assessing the effect on flood frequency of land use change via hydrological simulation (with uncertainty), J. Hydrol., 324, 141-153, doi:10.1016/j.jhydrol.2005.10.001, 2006.

Brouwers, L. and Boman, M.: A Computational Agent Model of Flood Management Strategies, in: Computational Methods for Agricultural Research: Advances and Applications, IGI Global, Hershey, PA, USA, 296-307, 2011.

Brown, C. and Wilby, R. L.: An alternate approach to assessing climate risks, Eos, Transactions American Geophysical Union, 93, 401-402, doi:10.1029/2012EO410001, 2012.
Burningham, K., Fielding, J., and Thrush, D.: "It'll never happen to me": understanding public awareness of local flood risk, Disasters, 32, 216-238, 2008.

Cashman, A. C.: Alternative manifestations of actor responses to urban flooding: case studies from Bradford and Glasgow, Water Sci. Technol., 60, 77-85, 2009.

Crooks, A., Castle, C., and Batty, M.: Key challenges in agent-based modelling for geo-spatial simulation, Computers, Environ. Urban Syst., 32, 417-430, 2008.

Dawson, R., Hall, J., Sayers, P., Bates, P., and Rosu, C.: Samplingbased flood risk analysis for fluvial dike systems, Stoch. Env. Res. Risk A., 19, 388-402, 2005.

Deffuant, G., Amblard, F., Weisbuch, G., and Faure, T.: How can extremism prevail? A study based on the relative agreement interaction model in: Journal of Artificial Societies and Social Simulation, Vol. 5, available at: http://jasss.soc.surrey.ac.uk/5/4/1.html (last access: 20 June 2013), 2002.

Defra: Taking forward a new Government strategy for flood and coastal erosion risk management in England First Government response to the autumn 2004: Making space for water consultation exercise, Defra, London, 45, 2004.

Defra: The UK Government Sustainable Development Strategy, London, 188, 2005.

Defra: Appraisal of flood and coastal erosion risk management: A Defra policy statement June 2009, Defra, London, 52, 2009.

Defra: Flood and Coastal Resilience Partnership Funding: Defra policy statement on an outcome-focused, partnership approach to funding flood and coastal erosion risk management Defra, London, 11, 2011.

Defra/EA: Understanding the risks, empowering communities, building resilience: the national flood and coastal erosion risk management strategy for England, The Stationary Office, London, 63, 2011.

DeMarzo, P. M., Vayanos, D., and Zwiebel, J.: Persuasion Bias, Social Influence, and Unidimensional Opinions, The Quarterly Journal of Economics, 118, 909-968, 2003.

Di Baldassarre, G., Castellarin, A., and Brath, A.: Analysis of the effects of levee heightening on flood propagation: example of the River Po, Italy, Hydrol. Sci. J., 54, 1007-1017, doi:10.1623/hysj.54.6.1007, 2009.

Di Baldassarre, G., Kooy, M., Kemerink, J. S., and Brandimarte, L.: Towards understanding the dynamic behaviour of floodplains as human-water systems, Hydrol. Earth Syst. Sci., 17, 3235-3244, doi:10.5194/hess-17-3235-2013, 2013a.

Di Baldassarre, G., Viglione, A., Carr, G., Kuil, L., Salinas, J. L., and Blöschl, G.: Socio-hydrology: conceptualising humanflood interactions, Hydrol. Earth Syst. Sci., 17, 3295-3303, doi:10.5194/hess-17-3295-2013, 2013b.

Downing, T., Moss, S., and Pahl-Wostl, C.: Understanding Climate Policy Using Participatory Agent-Based Social Simulation, in: Multi-Agent-Based Simulation, edited by: Moss, S. and Davidsson, P., Lecture Notes in Computer Science, Springer Berlin Heidelberg, 198-213, 2001.

Dyer, M.: Performance of flood embankments in England and Wales, Proc. ICE - Water Manage., 157, 177-186, 2004.

Eiser, R. J., Bostrom, A., Burton, I., Johnston, D. M., McClure, J., Paton, D., van der Pligt, J., and White, M. P.: Risk interpretation and action: A conceptual framework for 
responses to natural hazards, Int. J. Disaster Risk Red., 1, 5-16, doi:10.1016/j.ijdrr.2012.05.002, 2012.

Evans, E. P., Ashley, R., Hall, J. W., Penning-Rowsell, E. C., Saul, A., Sayers, P. B., Thorne, C. R., and Watkinson, A. R.: Foresight Future Flooding, Scientific Summary: Vol. 1: Future Risks and their Drivers, Office of Science and Technology, London, 2004a.

Evans, E. P., Ashley, R., Hall, J. W., Penning-Rowsell, E. C., Sayers, P. B., Thorne, C. R., and Watkinson, A. R.: Foresight Future Flooding. Scientific Summary: Vol. 2: Managing Future Risks, Office of Science and Technology, London 2004b.

Filatova, T., Parker, D. C., and Veen van der, A.: The Implications of Skewed Risk Perception for a Dutch Coastal Land Market: Insights from an Agent-Based Computational Economics Model, Agr. Resour. Econom. Rev., 40, 405-423, 2011.

Fraedrich, K., Blender, R., and Zhu, X.: Continuum climate variability: Long-term memory scaling, and 1/f-noise, Int. J. Modern Phys. B, 23, 5403-5416, 2009.

Geris, J., Ewen, J., and O'Connell, E.: Natural hydrological variability and its effect on flood impact of land use and management change: Insights from a multiscale monitoring experiment, J. Hydrol., submitted, 2013.

Grelot, F. and Barreteau, O.: Simulation of Resilience of an Insurance System to Flood Risk, Managing Resources of a Limited Planet, Sixth Biennial Meeting, Leipzig, Germany, 1-5 July, 8 pp., 2012.

Grothmann, T. and Reusswig, F.: People at Risk of Flooding: Why Some Residents Take Precautionary Action While Others Do Not, Nat. Hazards, 38, 101-120, 2006.

Gulati, G. J., Hadlock, C. R., and Gainsborough, J. F.: VODYS: An Agent-Based Model for Exploring Campaign Dynamics, Soc. Sci. Comput. Rev., 29, 250-272, 2011.

Hall, J. W., Evans, E. P., Penning-Rowsell, E. C., Sayers, P. B., Thorne, C. R., and Saul, A. J.: Quantified scenarios analysis of drivers and impacts of changing flood risk in England and Wales: 2030-2100, Global Environm. Change Part B, 5, 51-65, doi:10.1016/j.hazards.2004.04.002, 2003.

Hamill, L. and Gilbert, N.: Social Circles: A Simple Structure for Agent-Based Social Network Models, in: Journal of Artificial Societies and Social Simulation, Vol. 12, available at: http: //jasss.soc.surrey.ac.uk/12/2/3.html (last access: 20 June 2013), 2009

Harries, T. and Penning-Rowsell, E.: Victim pressure, institutional inertia and climate change adaptation: The case of flood risk, Global Environ. Change, 21, 188-197, 2011.

HM Treasury: The Green Book: Appraisal and Evaluation in Central Government, The Stationery Office, London, 118 pp., 2011.

Hosking, J. R. M. and Wallis, J. R.: Regional frequency analysis: an approach based on L-moments, Cambridge University Press, Cambridge, UK, 1997.

IPCC: Summary for Policymakers., in: Managing the Risks of Extreme Events and Disasters to Advance Climate Change Adaptation. A Special Report of Working Groups I and II of the Intergovernmental Panel on Climate Change, edited by: Field, C. B., Barros, V., Stocker, T. F., Qin, D., Dokken, D. J., Ebi, K. L., Mastrandrea, M. D., Mach, K. J., Plattner, G.-K., Allen, S. K., Tignor, M., and Midgley, P. M., Cambridge University Press, Cambridge, UK, and New York, NY, USA, 1-19, 2012.
Irvin, R. A. and Stansbury, J.: Citizen Participation in Decision Making: Is It Worth the Effort?, Public Administration Review, 64, 55-65, 2004.

Irwin, E. G.: New directions for urban economic models of land use change: Incorporating spatial dynamics and heterogeneity, J. Reg. Sci., 50, 65-91, doi:10.1111/j.1467-9787.2009.00655.x, 2010.

Johnson, C. L. and Priest, S. J.: Flood Risk Management in England: A Changing Landscape of Risk Responsibility?, Int. J. Water Resour. Develop., 24, 513-525, 2008.

Johnson, C., Penning-Rowsell, E., and Parker, D.: Natural and imposed injustices: the challenges in implementing "fair" flood risk management policy in England, Geogr. J., 173, 374-390, 2007.

Johnson, F., Westra, S., Sharma, A., and Pitman, A. J.: An Assessment of GCM Skill in Simulating Persistence across Multiple Time Scales, J. Clim., 24, 3609-3623, doi:10.1175/2011JCLI3732.1, 2011.

Jones, P. D., Lister, D. H., Wilby, R. L., and Kostopoulou, E.: Extended riverflow reconstructions for England and Wales, 18652002, Int. J. Climatol., 26, 219-231, doi:10.1002/joc.1252, 2006.

Kellens, W., Terpstra, T., and De Maeyer, P.: Perception and Communication of Flood Risks: A Systematic Review of Empirical Research, Risk Analysis, 33, 24-49, 2013.

Kim, J. E., Rheem, S. K. K., and Jeong, C. H.: Disaster Management of Local Government: Comparison between the UK and South Korea, Korea Association for Public Administration 2012 International Conference, Seoul, Korea, 27-29 June, 16 pp., 2012.

Koutsoyiannis, D.: Hurst-Kolmogorov Dynamics and Uncertainty, JAWRA J. Am. Water Resour. Assoc., 47, 481-495, 2011.

Krieger, K.: Norms, structures, procedures and variety in risk-based governance: the case of flood management in Germany and England, 4th Biennal Conference of the ECPR Standing Group on Regulation \& Governance at the University of Exeter, 27-29 June, 2012.

Krieger, K.: The limits and variety of risk-based governance: The case of flood management in Germany and England, Regul. Govern., 7, 236-257, 2013

Kurtz, C. F. and Snowden, D. J.: The new dynamics of strategy: Sense-making in a complex and complicated world, IBM Systems J., 42, 462-483, 2003.

Lane, S. N.: Climate change and the summer 2007 floods in the UK, Geography., 93, 91-97, 2008.

Lara, A., Saurí, D., Ribas, A., and Pavón, D.: Social perceptions of floods and flood management in a Mediterranean area (Costa Brava, Spain), Nat. Hazards Earth Syst. Sci., 10, 2081-2091, doi:10.5194/nhess-10-2081-2010, 2010.

Lavery, S. and Donovan, B.: Flood risk management in the Thames Estuary looking ahead 100 years, Philos. Trans. Royal Soc. A, 363, 1455-1474, 2005.

Lempert, R.: Agent-based modeling as organizational and public policy simulators, Proc. Natl. Acad. Sci. USA, 99, 7195-7196, 2002.

Ligtenberg, A., Wachowicz, M., Bregt, A. K., Beulens, A., and Kettenis, D. L.: A design and application of a multi-agent system for simulation of multi-actor spatial planning, J. Environ. Manage., 72, 43-55, 2004.

Liu, J., Dietz, T., Carpenter, S. R., Alberti, M., Folke, C., Moran, E., Pell, A. N., Deadman, P., Kratz, T., Lubchenco, J., Ostrom, E., Ouyang, Z., Provencher, W., Redman, C. L., Schneider, S. H., 
and Taylor, W. W.: Complexity of Coupled Human and Natural Systems, Science, 317, 1513-1516, 2007a.

Liu, J., Dietz, T., Carpenter, S. R., Folke, C., Alberti, M., Redman, C. L., Schneider, S. H., Ostrom, E., Pell, A. N., Lubchenco, J., Taylor, W. W., Ouyang, Z., Deadman, P., Kratz, T., and Provencher, W.: Coupled Human and Natural Systems, AMBIO: A J. Human Environ., 36, 639-649, 2007b.

Matalas, N.: Stochastic Hydrology in the Context of Climate Change, Clim. Change, 37, 89-101, 1997.

Matthews, R., Gilbert, N., Roach, A., Polhill, J. G., and Gotts, N.: Agent-based land-use models: a review of applications, Landscape Ecol., 22, 1447-1459, doi:10.1007/s10980-007-9135-1, 2007.

Mauget, S. A.: Intra- to Multidecadal Climate Variability over the Continental United States: 1932-99, J. Climate, 16, 2215-2231, doi:10.1175/2751.1, 2003a.

Mauget, S. A.: Multidecadal Regime Shifts in U.S. Streamflow, Precipitation, and Temperature at the End of the Twentieth Century, J. Climate, 16, 3905-3916, 2003b.

McEwen, L. and Jones, O.: Building local/lay flood knowledges into community flood resilience planning after the July 2007 floods, Gloucestershire, UK, Hydrol. Res., 43, 675-688, 2012.

McEwen, L., Krause, F., Hansen, J. G., and Jones, O.: Flood histories, flood memories and informal flood knowledge in the development of community resilience to future flood risk, BHS Eleventh National Symposium, Hydrology for a changing world, Dundee, 9-11 July, 2012a.

McEwen, L. J., Krause, K., Jones, O., and Garde-Hansen, J.: Sustainable flood memories, informal knowledges and the development of community resilience to future flood risk, WIT Press, Ashurst, UK, 253-264, 2012b.

Merz, B., Kreibich, H., Schwarze, R., and Thieken, A.: Review article "Assessment of economic flood damage", Nat. Hazards Earth Syst. Sci., 10, 1697-1724, doi:10.5194/nhess-10-16972010, 2010.

Mesa, O. J., Gupta, V. K., and O'Connell, P. E.: Dynamical System Exploration of the Hurst Phenomenon in Simple Climate Models, in: Extreme Events and Natural Hazards: The Complexity Perspective, American Geophysical Union, Washington D. C., 209-230, 2012.

Milly, P. C. D., Betancourt, J., Falkenmark, M., Hirsch, R. M., Kundzewicz, Z. W., Lettenmaier, D. P., and Stouffer, R. J.: Stationarity Is Dead: Whither Water Management?, 5863, 573-574, 2008.

Monticino, M., Acevedo, M., Callicott, B., Cogdill, T., and Lindquist, C.: Coupled human and natural systems: A multiagent-based approach, Environ. Modell. Softw., 22, 656-663, 2007.

Moss, S., Downing, T., and Rouchier, J.: Demonstrating the Role of Stakeholder Participation: An Agent Based Social Simulation Model of Water Demand Policy and Response, Centre for Policy Modelling, Manchester Metropolitan University, Manchester, UK, 2001.

Munich, Re: Natural catastrophes 2007 Analyses, assessments, positions Munich, 54, 2008.

Naess, L. O., Bang, G., Eriksen, S., and Vevatne, J.: Institutional adaptation to climate change: Flood responses at the municipal level in Norway, Global Environ. Change, 15, 125-138, 2005.
Nancarrow, B. E. and Syme, G. J.: Fairness principles in allocating water: integrating views of different agents, International Congress "Complexity and Integrated Resources management", Univ. Osnabrück, 14-17 June, 172-176, 2004.

Ntegeka, V. and Willems, P.: Trends and multidecadal oscillations in rainfall extremes, based on a more than 100-year time series of 10 min rainfall intensities at Uccle, Belgium, Water Resour. Res., 44, W07402, doi:10.1029/2007WR006471, 2008.

O'Connell, P. E.: Catchments as coupled human and natural systems, Conference on Integrated Assessment of Water Resources and Global Change: A North-South Analysis, Bonn, Germany, 23-25 February, 2005.

O'Connell, E., Blenkinsop, S., O’Donnell, G., and Hall, J.: Evaluating strategies for adaptation investment in a highly variable climate., BHS Third International Symposium: Role of Hydrology in Managing Consequences of a Changing Global Environment, Newcastle upon Tyne, 19-23 July, 552-557, 2010a.

O'Connell, E., Ewen, J., and O'Donnell, G.: Strategic Overview of Land Use Management in the Context of Catchment Flood Risk Management Planning, in: Flood Risk Science and Management, edited by: Pender, G. and Faulkner, H., Wiley-Blackwell, 2010 b.

O'Connell, P. E.: A simple stochastic modelling of Hurst's Law, IAHS Mathematical Models in Hydrology Symposium, Warsaw, 169-187, 1971.

O'Connell, P. E.: Stochastic modeling of long-term persistence in stream flow sequences, Imperial College of Science and Technology, London, 1974.

O'Connell, P. E. and O'Donnell, G. M.: Modelling Water Resources and Flood Risk Management Adaptation in a Highly Variable Climate: Is Stationarity Really Dead?, Hydrol. Sci. J., submitted, 2013.

O'Connell, P. E., Ewen, J., O’Donnell, G., and Quinn, P.: Is there a link between agricultural land-use management and flooding?, Hydrol. Earth Syst. Sci., 11, 96-107, doi:10.5194/hess-11-962007, 2007.

O'Neill, J. and O'Neill, M.: Social justice and the future of flood insurance, Joseph Rowntree Foundation, York, 2012.

Parker, D. J.: Floodplain development policy in England and Wales, Appl. Geogr., 15, 341-363, 1995.

Parliamentary Select Committee: Evidence from the Local Government Association (LGA) on Flooding, House of Commons, London, 2013.

Pattison, I. and Lane, S. N.: The relationship between Lamb weather types and long-term changes in flood frequency, River Eden, UK, Int. J. Climatol., 32, 1971-1989, 2012.

Pearce, D.: Cost benefit analysis and environmental policy, Oxf. Rev. Econ. Policy, 14, 84-100, 1998.

Pellizzari, P.: Complexities and simplicity: a review of agent-based artificial markets, Giornata di studi in onore di Giovanni Castellani, Venice, 26 September, 211-221, 2005.

Penning-Rowsell, E., Johnson, C., and Tunstall, S.: "Signals" from pre-crisis discourse: Lessons from UK flooding for global environmental policy change?, Global Environ. Change, 16, 323339, 2006.

Porter, J. and Demeritt, D.: Flood-risk management, mapping, and planning: the institutional politics of decision support in England, Environ. Plann.-Part A, 44, 2359-2378, 2012.

Raubal, M.: Ontology and epistemology for agent-based wayfinding simulation, Int. J. Geogr. Inform. Sci., 15, 653-665, 2001. 
Robson, A. J., Jones, T. K., Reed, D. W., and Bayliss, A. C.: A study of national trend and variation in UK floods, Int. J. Climatol., 18, 165-182, 1998.

Scolobig, A., Marchi, B., and Borga, M.: The missing link between flood risk awareness and preparedness: findings from case studies in an Alpine Region, Nat. Hazards, 63, 499-520, doi:10.1007/s11069-012-0161-1, 2012.

Sivapalan, M., Savenije, H. H. G., and Blöschl, G.: Sociohydrology: A new science of people and water, Hydrol. Process., 26, 1270-1276, 2012.

Svensson, C. and Jones, D. A.: Dependence between extreme sea surge, river flow and precipitation in eastern Britain, Int. J. Climatol., 22, 1149-1168, 2002.

ten Brinke, W. B. M., Saeijs, G. E. M., Helsloot, I., and van Alphen, J.: Safety chain approach in flood risk management, Proc. ICEMunicipal Engineer, 161, 93-102, 2008.

Verdon, D. C. and Franks, S. W.: Long-term behaviour of ENSO: Interactions with the PDO over the past 400 years inferred from paleoclimate records, Geophys. Res. Lett., 33, L06712, doi:10.1029/2005GL025052, 2006.
Villarini, G., Smith, J. A., Vitolo, R., and Stephenson, D. B.: On the temporal clustering of US floods and its relationship to climate teleconnection patterns, Int. J. Climatol., 33, 629-640, doi:10.1002/joc.3458, 2013.

Vojinović, Z. and Abbott, M. B.: Flood risk and social justice: From quantitative to qualitative flood risk assessment and mitigation, IWA Publishing (International Water Assoc), London, 2012.

Wachinger, G., Renn, O., Begg, C., and Kuhlicke, C.: The Risk Perception Paradox-Implications for Governance and Communication of Natural Hazards, Risk Anal., 33, 1049-1065, doi:10.1111/j.1539-6924.2012.01942.x, 2013.

Whatmore, S. J. and Landström, C.: Flood apprentices: an exercise in making things public, Econ. Soc., 40, 582-610, 2011.

Wiering, M. A. and Driessen, P. P. J.: Beyond the art of diking: interactive policy on river management in The Netherlands, Water Pol., 3, 283-296, 2001.

Wilkinson, M. E., Quinn, P. F., and Welton, P.: Runoff management during the September 2008 floods in the Belford catchment, Northumberland, J. Flood Risk Manage. 3, 285-295, 2010. 